\title{
Analisis Marjin dan Efisiensi Saluran Pemasaran Produksi Bawang Merah (Allium ascolanicum L.) Di Desa Banti Kecamatan Baraka Kabupaten Enrekang
}

\author{
Margin and Efficiency Analiysis of Onion Production Marketing Channels (Allium \\ Ascolanicum L.) Banti Village Baraka Districts Enrekang Regency \\ Irmayani $^{{ }^{*}}$, Hasnawati ${ }^{2}$, dan A. Erna Sriwahyuningsih ${ }^{3}$ \\ *Email: irmaumpar@yahoo.co.id \\ ${ }^{1}$ Program Studi Agribisnis, Fak. Pertanian, Peternakan dan Perikanan, Universitas Muhammadiyah Parepare
}

Diterima: 22 Mei 2021 / Disetujui: 02 Agustus 2021

\begin{abstract}
ABSTRAK
Penelitian ini bertujuan menganalisis marjin dan efisiensi pemasaran produksi bawang merah desa Banti Kecamatan Baraka Kabupaten Enrekang.Penelitian ini dilakukan selama tiga bulan yaitu bulan September sampai November 2020. Hasil penelitian menunjukkan bahwa terdapat dua saluran pemasaran bawang merah didesa Banti Kecamatan Baraka Kabupaten Enrekang yaitu: Saluran I : Petani ke Pedagang pengumpul kemudian ke Pedagang pengecer lalu Konsumen akhir Saluran II : Petani ke Pedagang pengecer kemudian ke Konsumen akhir, Marjin pemasaran tiap lembaga pemasaran yaitu saluran I Petani memperoleh keuntungn sebesar Rp 2.997 /Kg, pedagang pengumpul sebesar Rp $1.562 / \mathrm{Kg}$, pedagang pengecer sebesar Rp 1.572/Kg dan saluran II Petani memperoleh keuntungan sebesar Rp $2.942 / \mathrm{Kg}$ pedagang pengecer $\mathrm{Rp} 2000$ /Kg. Tingkat efisiensi saluran pemasaran bawang merah desa Banti menunjukkan bahwa saluran II lebih efisiensi debanding saluran I dengan nilai 3,85\% dan saluran II 4.59\%.
\end{abstract}

Kata Kunci: Marjin pemasaran, EfIsiensi Saluran Pemasaran, Bawang Merah

\section{ABSTRACT}

This study aims to analyze the margin and marketing efficiency of shallot production in Banti Village, Baraka District, Enrekang Regency. This research was conducted for three months, from September to November 2020. The results showed that there were two marketing channels for shallots in Banti Village, Baraka District, Enrekang Regency, namely: Channel I : Farmers to collecting traders then to retailers and then final consumersChannel II : Farmers to retailers then to final consumers The marketing margin of each marketing agency, namely channel I Farmers get a profit of IDR 2,997 / Kg, collectors IDR 1,562 / Kg, retailers IDR 1,572 / Kg and channel II Farmers get a profit of Rp. 2,942/ kg retailers $R p .2000 / \mathrm{kg}$. The efficiency level of the Banti village's shallot marketing channel shows that channel II is more efficient with channel I debanding with a value of $3.85 \%$ and channel II is $4.59 \%$

Keywords: Marketing Margin, Marketing Channel Efficiency, Shallots

\section{A. PENDAHULUAN}

Bawang merah merupakan salah satu tanaman hortikultura komoditas sayuran yang tumbuh secara baik di dataran tinggi maupun dataran rendah apabila tempatnya terbuka, cahaya matahari terpenuhi lebih dari 12 jam dengan iklim kering dengan suhu agak panas dan tekstur tanahnya remah, sedang dan liat. Di Indonesia tanaman bawang merah sudah sejak lama diusahakan oleh petani sebagai usahatani komersial terutama di Desa Banti 
Kecamatan Baraka Kabupaten Enrekang Tingkat permintaan dan kebutuhan konsumsi bawang merah yang tinggi menjadikan komoditas ini menguntungkan jika diusahakan. Konsumsi bawang merah di Indonesia per kapita per tahun mencapai 4,56 kilogram atau 0,38 kilogram per kapita per bulan. Tingginya permintaan bawang merah dipengaruhi oleh peningkatan jumlah penduduk, peningkatan industri pengolahan, industri parawisata, restoran, serta pasar yang mengiginkan jenis tanaman hortikultura dengan mutu yang baik. Oleh karna itu produksi bawang merah di Desa Banti kecamatan Baraka Kabupaten Enrekang yang terus ditingkatkan agar kebutuhan masyrakat terpenuhi dan berpeluang juga untuk ekspor.

Budidaya bawang merah dilakukan diseluruh wilayah di Kabupaten Enrekang. Salah satu penghasil bawang merah terbanyak adalah di Desa Banti Kecamatan Baraka yang memiliki beberapa dusun dan hampir petaninya dominan petani bawang merah.

Tabel 1. Luas dan produksi Bawang Merah per Kecamtan Kabupaten Enrekang Tahun 2019

\begin{tabular}{llcc}
\hline No & Kecamatan & $\begin{array}{c}\text { Luas } \\
\text { Lahan } \\
\text { (Ha) }\end{array}$ & $\begin{array}{c}\text { Produksi } \\
\text { (Ton) }\end{array}$ \\
\hline 1 & Maiwa & - & - \\
2 & Bungin & 7 & 180 \\
3 & Enrekang & 38 & 3.224 \\
4 & Cendana & - & - \\
5 & Baraka & 610 & 73.688 \\
6 & Buntu batu & 62 & 6.160
\end{tabular}

\begin{tabular}{llcc}
7 & Anggeraja & 4.575 & 604.900 \\
8 & Malua & 286 & 22.410 \\
9 & Alla & 330 & 69.805 \\
10 & Curio & 2 & 650 \\
11 & Masalle & 221 & 18.032 \\
12 & Baroko & 23 & 1.674 \\
\hline & Jumlah & 6.154 & 800.723
\end{tabular}

Sumber Data : Dinas Pertanian Kabupaten Enrekang Tahun 2020

Tabel 1 menunjukkan bahwa salah satu kecamatan merupakan penghasil Bawang Merah adalah Kecamatan Baraka dengan jumlah produksi sebesar 73.688 ton pada tahun 2019. Akan tetapi kondisi tersebut mengalami permasalahan pada saat musim panen yang dilakukan hampir bersamaan, menyebabkan produksi Bawang Merah melimpah pada musim panen, sehingga mengakibatkan turunnya harga jual Bawang Merah. Selain itu tidak menentunya cuaca menyebabkan turunnya produktivitas Bawang Merah juga menjadi masalah dalam pemasaran hasil pertanian. Pemasaran Bawang Merah di Desa Banti Kecamatan Baraka Kabupaten Enrekang yaitu dari petani sendiri yang akan menjualnya dari pedagang pengumpul dan pedangang pengumpul yang akan menjualnya lagi ke pedagang pengecer dan akhirnya pada konsumen. Dan ada sebagian petani yang menjual langsung ke pasar dengan produksi yang rendah diakibatkan pedagang pengumpul tidak mau mengambil langsung di lokasi petani di akibatkan tingginya biaya yang digunakan. 
B. METODE PENELITIAN

\section{Lokasi dan Waktu Penelitian}

Penelitian ini akan dilaksanakan di Desa Banti Kecamatan Baraka Kabupaten Enrekang. Penelitian ini akan dilaksanakan selama dua bulan yaitu bulan September sampai dengan bulan November 2020.

\section{Teknik Penentuan Sampel}

Penentuan sampel lembaga pemasaran dilakukan dengan menggunakan metode purposive sampling yaitu teknik untuk menentukan sampel peneliti dengan beberapa pertimbangan tertentu yang bertujuan agar data yang diperoleh bisa lebih representatif (sugiyono, 2010). Jumlah responden dalam penelitian ini berjumlah 25 orang yang di pilih secara sengaja (purposive sampling) terdiri dari 7 petani 8 orang pedagang pengumpul dan 10 orang pedagang pengecer.

\section{Teknik Pengumpulan Data}

Teknik pengumpulan data yang digunakan adalah sebagai berikut :

a. Observasi merupakan teknik pengumpilan data yang dilakukan dengan mengambil secara langsung kegiatan yang dilakukan oleh objek penelitian.

b. Wawancara merupakan pengumpulan data yang langsung dalam bentuk tanya jawab dengan responden.

c. Quisionar yaitu pertanyaan tertulis yang diajukan kepada responden. Dalam menggunakan quisioner, maka peneliti akan mendapatkan data secara faktual.

d. Dokumentasi yaitu pengumpulan data melalui jurnal, hasil penelitia terdahulu buku dan literatur yang ada kaitannya dengan penelitian.

\section{Analisis Data}

Adapun metode analisis data yang digunakan pada penelitian ini adalah:

a. Analisis data dalam penelitian ini yaitu mengelompokkan dan membuat suatu urutan sehingga data mudah di baca dan dipahami. Data yang terkumpul kemudian dilakukan pengeditan dan perhitungan data mentah. Data tersebut kemudian dikelompokkan sebagian dengan indikator-indikator yang akan dijadikan ukuran penelitian. Data kuantitatif diolah dengan manggunakan alat hitung (kalkulator).

b. Analisis marjin pemasaran bawang dengan menggunakan rumus sebagai berikut :

$$
\begin{aligned}
& \mathrm{M}_{\mathrm{i}}=\mathrm{P}_{\mathrm{Si}}-\mathrm{P}_{\mathrm{bi}} \\
& \mathrm{M}_{\mathrm{i}}=\mathrm{C}_{\mathrm{i}}+\pi_{\mathrm{i}} \\
& \pi=\mathrm{M}-\mathrm{B}
\end{aligned}
$$


Keterangan :

$\mathrm{M}_{\mathrm{i}}=$ Margin pemasaran pada tingkat ke-I

$\mathrm{P}_{\mathrm{si}}=$ Harga jual pada tingkat ke-I

$\mathrm{Pbi}=$ Harga beli pada pasar tingkat ke-i

$\mathrm{Ci}=$ Biaya pemasaran pada tingkat ke-i

$\Pi_{\mathrm{i}}=$ Keuntungan pemasaran pada pasar tingkat ke-i

Proses pengaliran bawang merah dari prtani ke konsumen setiap lembaga menarik keuntungan dengan menggunakan rumus (Rupiah,2008)

$\Pi=$ Besarnya keuntungan yang ditarik lembaga pemasaran $(\mathrm{Rp} / \mathrm{Kg})$

$\mathrm{M}=$ Marjin pemasaran $(\mathrm{Rp} / \mathrm{Kg})$

$\mathrm{B}=$ Biaya pemasaran $(\mathrm{Rp} / \mathrm{Kg})$

Untuk menghitung bagian yang diterima yang diterima masing-masing lembaga pemasaran ( shere marjin) maka digunakan rumus :

$$
s m=\frac{p p}{m m} \times 100 \%
$$

Ketarangan :

sm : Shere Marjin (\%)

$\mathrm{pp}$ : Harga yang diterima produsen $(\mathrm{Rp})$

$\mathrm{mm}$ : Harga yang dibayar oleh konsumen (Rp), (Pabbo,2013)

Untuk menghitung efisiensi

pemasaran digunakan rumus

$$
E P=\frac{T B}{T N P} \times 100 \%
$$

Dimana pemasaran akan semakin efisien apabila nilai efisien pemasaran (Ep) semakain kecil, (Roesmawaty,2011). Indikator efisien pemasaran menurut Ningsih (2012) dapat diukur dengan kriteria sebagai berikut :

a. Jika share yang diterima petani lebih besar dari shere marjin pemasarannya maka saluran pemasaran tersebut dikategorikan efisien.

b. Jika shere harga yang diterima petani lebih kecil dari shere marjinpemasarannya, maka saluran pemasaran tersebut dikategorikan tidak efisien.

Kaidah keputusan pada efisiensi pemasaran ini menurut Roesmawaty (2011), adalah :

a. $0-33 \%=$ Efisiensi

b. $34-67 \%=$ Kurang Efisien

c. $\quad 68-100 \%=$ Tidak Efisien

\section{HASIL DAN PEMBAHASAN}

\section{Analisis Marjin Pemasaran}

Pada Tabel 2 menunjukkan bahwa di tingkat petani yang menjual langsung hasil panen bawang merah ke pedagang pengumpul dan tidak mengeluarkan biaya pemasaran, sebab pedagang pengumpul langsung membelinya di rumah petani sehingga tidak ada biaya dikeluarkan kecuali biaya produksi. Pada tabel 8 bisa dilihat biaya rata-rata produksi bawang merah pada saluran ke I sebesar Rp 9.503 $/ \mathrm{Kg}$, persentase biaya produksi terhadap harga jual sebesar $60,20 \%$, petani mendapat keuntungan sebesar Rp 2.997/Kg. Hal ini sesuai dengan penelitian terdahulu arwanti (2016), dimana para petani tidak mengeluarkan biaya pemasaran, petani menyediakan hasil panennya dan biaya 
karung atau pengemasan ditanggung oleh pedagang pengumpul yang membeli dari petani. Marjin pemasaran bawang merah dari petani ke pedagang pengumpul dapat dilihat pada Tabel 2

Tabel 2. Analisis Marjin Pemasaran Bawang Merah Dari Petani Pengumpul, Pengecer, Konsumen Akhir-Pengecer-Konsumen Akhir

\begin{tabular}{|c|c|c|c|}
\hline Unsur & $\begin{array}{c}\text { Biaya/ } \\
\text { Kg }\end{array}$ & Harga & $\begin{array}{c}\text { Shere } \\
\%\end{array}$ \\
\hline \multicolumn{4}{|l|}{ Petani } \\
\hline Biaya produksi & 9.503 & & 60,20 \\
\hline Harga Jual & & 12.500 & 79,18 \\
\hline Keuntungan & 2.997 & & \\
\hline Harga Beli & & 12.563 & 79,57 \\
\hline \multicolumn{4}{|l|}{ Pengumpul } \\
\hline Biaya pemasaran & 227 & & 79,58 \\
\hline -Transfortasi & 102 & & \\
\hline -Tenaga Keraja & 16 & & 2,66 \\
\hline -Retribusi & 75 & & \\
\hline -Kemasan & 420 & & 7,23 \\
\hline Total Biaya & 1.142 & & 9,89 \\
\hline Keuntungan & 1.562 & & \\
\hline $\begin{array}{l}\text { Marjin pemasaran } \\
\text { Harga Jual }\end{array}$ & & 14.125 & 89,47 \\
\hline Harga Beli Pengecer & & 14.214 & 90,04 \\
\hline \multicolumn{4}{|l|}{ Biaya Pemasaran } \\
\hline -Angkut & 199 & & \\
\hline -Retribusi & 37 & & \\
\hline -Pengemasan & 67 & & \\
\hline -Penyusustan & 3,13 & & \\
\hline Total Biaya & 306,13 & & 1,93 \\
\hline Keuntungan & 1.266 & & 8,02 \\
\hline Marjin pemasaran & 1.572 & & 9,95 \\
\hline Harga jual & & 15.786 & 100 \\
\hline Konsumen akhir & & 15.786 & 100 \\
\hline
\end{tabular}

Komponen biaya pemasaran yang harus dikeluarkan oleh pedagang pengumpul hingga bawang merah sampai ke pasar meliputi biaya, transfortasi, tenaga kerja, retribusi dan kemasan. Biaya yang dikeluarkan pedagang pengumpul untuk membeli bawang merah dari petani rata-rata sebasar Rp 12.563 / Kg dengan persentase harga beli sebesar $79,57 \%$ terhadap harga jual. Biaya transfortasi merupakan biaya yang harus dikeluarkan sekali angkut dengan biaya rata-rata $\mathrm{Rp} 361.125$ / 1.594 $\mathrm{Kg}$ muatan bawang merah atau biaya transfortasi yang dikeluarkan pedagang pengumpul berkisar $\mathrm{Rp} 227 / \mathrm{Kg}$ dengan menggunakan mobil jenis pick up.

$$
\text { Pedagang pengumpul juga }
$$
mengelurkan biaya tenaga kerja , yakni biaya pengangkutan dan membersihkan bawang dari akarnya rata-rata sebesar Rp 162.500/ hari, sehingga rata-rata biaya tenaga kerja yang dikeluarkan sebesar $\mathrm{Rp}$ 102 /Kg. Biaya retribusi adalah biaya yang dikeluarkan selama dalam perjalanan sekali angkut, biaya ini meliputi parkir, karcis masuk dan keluar, biaya yang harus dikeluarkan sebesar Rp 25.000 sekali pengangkutan, jadi rata-rata retribusi yang harus dikeluarkan sebesar Rp 16 /Kg. Biaya pembelian karung adalah biaya yang harus dikelurkan untuk mengemas bawang merah agar tidak tercecer sampai ke tujuan ratarata biaya yang dikeluarkan sebesar $\mathrm{Rp}$ $75 / \mathrm{Kg}$. Marjin pemasaran yang diterima pedagang pengumpul bawang merah sebesar Rp 1.562 /Kg dengan biaya pemasaran yang harus dikelurkan sebesar Rp 420 /Kg maka keuntungan yang didapat oleh pedagang pengumpul sebesar Rp $1.142 / \mathrm{Kg}$.

Hal ini sesuai dengan pendapat Maysari (2017), tinggi atau rendahnya 
marjin tataniaga suatu produk dapat dipengaruhi oleh beberapa faktor seperti pengangkutan, penyimpanan, dan lain sebagainya. Marjin pemasaran bawang merah dari pengumpul ke pengecer dengan acuan pasar baraka dapat dilihat pada Tabel 3.

Biaya pemasaran dikelurkan oleh pedagang pengecer meliputi biaya, tenaga kerja, retribusi, pengemasan dan penyusutan. Biaya yang dikeluarkan pedagang pengecer di Pasar Baraka untuk membeli bawang merah ke pedagang pengumpul rata-rata sebesar Rp $14.214 / \mathrm{Kg}$ berdasarkan hasil analisis marjin pemasaran juga terlihat persentase harga beli sebesar 90,04\% terhadap harga jual pedagang pengecer mengelurkan biaya pemasaran sesuai dengan perlakuan yang dilakukan dalam membeli bawang merah dari pedagang pengumpu hingga dijual lagi ke tangan konsumen.

Biaya tenaga kerja adalah biaya yang harus dikeluarkan oleh pedagang pengecer untuk mengangkut bawang merah sampai ke tempat jualan yaitu Biaya yang dikelurkan untuk sekali angkut sekitar Rp 54.286 dengan biaya rata-rata Rp 199 /Kg bawang merah. Biaya rata-rata retribusi yang harus dikeluarkan pedagang pengecer sekitar Rp 10.000 atau sebesar Rp 37 /Kg.
Biaya rata-rata pembelian kantong (pengemasan) yang harus dikeluarkan sebesar Rp 18.286 atau Rp 67 /Kg. Biaya penyusutan adalah komponen biaya yang terjadi ketika bawang merah mulai membusuk saat akan dijual dengan memisahkan yang masih layak jual dengan yang sudah mulai rusak yaitu rata-rata sebesar Rp 1.000 atau Rp 3,13 /Kg. Marjin pemasaran yang diperoleh pedagang pengecer bawang merah sebesar Rp 1.572 dengan persentase marjin pemasaran terhadap harga jual sebesar 9,95\%. Biaya pemasaran yang dikelurkan $\mathrm{Rp} 306,13$ /Kg dengan persentase biaya pemasaran terhadap harga jual adalah 1,93 \%, maka keuntungan yang didapat oleh pedagang pengecer bawang merah adalah Rp 1.266 $/ \mathrm{Kg}$ atau 8,02 \% terhadap harga jual. Tinggi marjin menurut Ansar dalam Pabbo(2013) dapat disebabkan olrh berbagai faktor yang berpengaruh dalam proses tataniaga antara lain ketersedian fisik tataniaga meliputi pengangkutan, penyimpanan, pengolahan dan resiko kerusakan.

Tabel 3. Analisis Marjin Pemasaran Bawang Meran dari Petani Pengecer, Konsumen Akhir

\begin{tabular}{lrcc}
\hline \multicolumn{1}{c}{ Unsur } & $\begin{array}{c}\text { Biaya/ } \\
\text { Kg }\end{array}$ & Harga & $\begin{array}{c}\text { Share } \\
\text { \% }\end{array}$ \\
\hline Petani & & & \\
Biaya produksi & 9.400 & & 62,60 \\
- Transfortasi & 250 & & \\
- Pengemasan & 75 & & \\
Total Biaya & 325 & & 2,16 \\
Keuntungan & 2.942 & & 19,61 \\
Harga Jual & & 12.667 & 84,44 \\
\hline
\end{tabular}




\begin{tabular}{|c|c|c|c|}
\hline & 13.000 & 86,66 \\
\hline \multicolumn{4}{|l|}{ Pengecer } \\
\hline Biaya & 125 & & \\
\hline - Tenaga Kerja & 4 & & \\
\hline - Penyusutan & 84 & & \\
\hline - Pengemasan & 40 & & \\
\hline - Retribusi & 253 & & 1,68 \\
\hline Total Biaya & 2000 & & 13,33 \\
\hline Marjin & 1.747 & & 11,64 \\
\hline Keuntungan & & 15.000 & 100 \\
\hline \multicolumn{4}{|l|}{ Hargadi Tingkat } \\
\hline \multicolumn{4}{|l|}{ Konsumen } \\
\hline Konsumen & & 15.000 & 100 \\
\hline Akhir & & & \\
\hline
\end{tabular}

Tabel 3 menunjukkan bahwa petani langsung menjual hasil produksinya ke pedagang pengecer dengan harga rata-rata Rp 12.667 per kg sehingga shere yang di terima petani sebesar $84,44 \%$, hal ini dikarenakan petani harus membawa hasil produksinya ke pasar baraka untuk di jual ke pedagang pengecer dan petani mengeluarkan biaya pengemasan dan transportasi. Biaya pengemasan yang harus dikeluarkan petani sebesar $\mathrm{Rp} 75 / \mathrm{kg}$ dan biaya transfortasi sebesar Rp 250 / kg, sehingga total biaya pemasaran yang dikeluarkan petani sebesar Rp 325 atau 2,16\%. Dan petani mendapatkan keuntungan pemasaran sebesar Rp 2.942 $/ \mathrm{Kg}$ atau 19,61\%. Sedangkan pengecer membeli bawang merah dari petani rata-rata sebesar Rp 13.000 /Kg kemudian biaya tenaga kerja yang harus dikeluarkan pedagang pengecer sebesar $\mathrm{Rp} 125 / \mathrm{Kg}$, biaya penyusutan sebesar $\mathrm{Rp} 4 / \mathrm{Kg}$, biaya pengemasan sebesar $\mathrm{Rp} 84,32$ /Kg dan biaya retribusi sebesar $\mathrm{Rp} 40 / \mathrm{Kg}$ sehingga biaya pemasaran yang harus dikeluarakan oleh pedagang pengecer sebesar Rp 253,32 $/ \mathrm{Kg}$ dan kauntungan yang diperoleh pedagang pengecer sebesar $\mathrm{Rp} 1.742 / \mathrm{Kg}$ atau $11,64 \%$

Dari kedua analisis marjin pemasaran saluran pemasaran di atas terlihat bahwa terjadi perbedaan harga jual, harga beli dan keuntungan terhadap lembaga pemasaran yaitu, petani, pedagang pengumpul, dan pedagang pengecer. Pada saluran pertama terjadi transaksi antara petani, pedagang pengumpul dan pedagang pengecer hingga sampai ke konsumen akhir, hal ini menyebabkan petani mendapatkan keuntungan sebesar Rp $2.997 / \mathrm{kg}$ dari hasil penjualan bawang merah dan seadangkan pada saluran kedua petani mendapatkan keuntungan sebesar Rp $2.942 / \mathrm{kg}$.

Pada umumnya keuntungan yang diterima petani lebih sedikit apabila petani yang akan menjual bawang merah ke pedagang pengecer karena petani harus mengeluarkan biaya transfortasi dan biaya pengemasan. Sedangkan apabila petani menjualanya ke pedagang pengumpul maka petani akan mendapatkan keuntungan lebih tinggi karna petani tidak mengeluarkan biaya pemasaran dibandingkan petani menjual langsung ke pedagang pengecer karna membutuhkan biaya pengemasan dan 
trensfor untuk sampai ke tempat pedagang pengecer.

\section{Saluran Pemasaran}

Saluran pemasaran bawang merah di Desa Banti terdiri dari 2 saluran. Saluran pertama menggambarkan petani menjual hasil produksinya ke pedagang pengumpul, dan saluran kedua, petani langsumg menjual hasil produksinya ke pedagang pengecer. Harga jual bawang merah rata-rata dari petani ke pedagang pengecerl $\mathrm{Rp} 12.667 / \mathrm{kg}$ , dan harga beli bawang merah rata-rata dari petani ke pedagang pengecer adalah $\mathrm{Rp}$ $13.000 / \mathrm{kg}$. Harga jual bawang merah ratarata dari pedagang pengumpul ke pedagang pengecer adalah $\mathrm{Rp} 14.125 / \mathrm{kg}$, dan harga jual pedagang pegecer ke konsumen akhir adalah $\operatorname{Rp} 15.786 / \mathrm{kg}$.

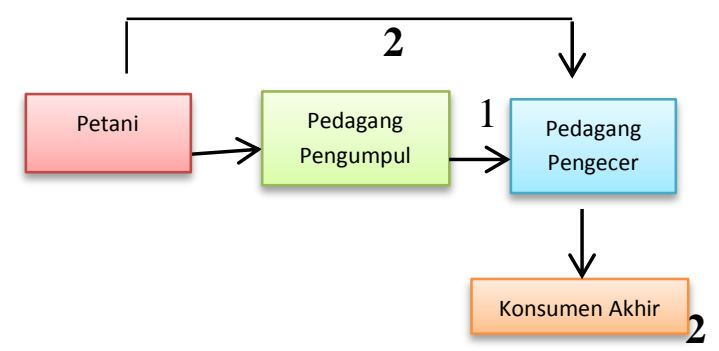

Keterangan :

(1) $=$ Saluran $1(2)=$ Saluran 2

Gambar 3. Saluran Pemasaran bawang merah di Desa Banti

\section{Efisiensi Pemasaran Bawang Merah}

Efisiensi pemasaran indikasih kesejahteraan para pelaku kegiatan ekonomi produksi pertanian yang meluputi produsen, lembaga pemasaran dan konsumen (Ardhiana, 2014). Tinggi rendahnya efisien saluran pemasaran juga ikut mempengaruhi harga di tangan petani (Muslim dan Darwis, 2012). Berdasarkan analisis marjin pemasaran bawang merah di Desa Banti Kecamatan Baraka Kabupaten Enrekang kedua saluran pemasaran sudah efisien. Hal ini dilihat dari share marjin pemasaran dimana share yang diterima tiap-tiap lembaga lebih besar dari share marjin. sesuai dengan yang dikemukakan oleh Roesmawaty (2011) bahwa $0-33 \%$ dikatakan efisien, $34-67 \%$ kurang efisien, $68-100 \%$ tidak efisien, Sedangkan tingkat efisiensi yang diperoleh dalam saluran pemasaran tersebut dibawah dari angka 33 $\%$.

1.Tingkat Efisiensi Pemasaran Saluran I :

$$
\begin{aligned}
& E p=\frac{\text { Total Biaya }}{\text { Total Nilai produk }} \times 100 \\
& E p=\frac{420+306,13}{15.786} \times 100 \\
& E p=4,59
\end{aligned}
$$

\section{Tingkat Efisisensi Pemasaran Saluran II}

$$
\begin{aligned}
& E p=\frac{\text { Total Biaya }}{\text { Total Nilai produk }} \times 100 \\
& E p=\frac{325+253,32}{15.000} \times 100 \\
& E p=3,85
\end{aligned}
$$




\begin{tabular}{|c|c|c|c|c|c|}
\hline $\begin{array}{c}\text { Lembaga } \\
\text { Pemasaran }\end{array}$ & $\begin{array}{c}\text { Harga } \\
\text { beli } \\
\text { (Rp/Kg) } \\
\end{array}$ & $\begin{array}{c}\text { Harga } \\
\text { Jual } \\
\text { (Rp/Kg) } \\
\end{array}$ & $\begin{array}{c}\text { Biaya } \\
\text { Pemasaran } \\
(\mathbf{R p} / \mathrm{Kg}) \\
\end{array}$ & $\begin{array}{c}\text { Keuntungan } \\
\text { (Rp/Kg) }\end{array}$ & $\begin{array}{c}\text { MarjinPemasaran } \\
(\mathrm{Rp} / \mathrm{Kg})\end{array}$ \\
\hline \multicolumn{6}{|l|}{ Saluran I } \\
\hline 1 Petani & - & 12.500 & - & 2.997 & - \\
\hline $2 \quad$ Pedagang & 12.563 & 14.125 & 420 & 1.142 & 1.562 \\
\hline Pengumpul & & & & & \\
\hline 3 Pedagang Pengecer & 14.214 & 15.786 & 306,13 & 1.267 & 1.572 \\
\hline \multicolumn{6}{|l|}{ Saluran II } \\
\hline 1 Petani & - & 12.667 & 325 & 2.942 & - \\
\hline 2 Pedagang Pengecer & 13.000 & 15.000 & 253,32 & 1.747 & 2.000 \\
\hline
\end{tabular}

\section{KESIMPULAN DAN SARAN}

Hasil penelitian dan pembahasan dapat disimpulkan bahwa pemasaran bawang merah di Desa Banti ke Pasar Baraka terdapat dua pola alur pemasaran, Saluran I Petani pedagang pengumpul pedagang pengecer ke konsumen akhir, Saluran II petani pedagang pengecer ke konsumen akhir.

Berdasarkan hasil analisis marjin pemasaran terdapat perbedaan perolehan marjin pemasaran anatara tiap lembaga pemasaran, yakni Pada Saluran I Petani memperoleh keuntungan Rp $2.997 / \mathrm{Kg}$, pengumpul Rp 1.562 /Kg, pedagang pengecer Rp 1.572 /Kg, Saluran II Petani mendapatkan keuntungan sebesar $\mathrm{Rp}$ $2.942 / \mathrm{Kg}$ dan pedagang $\mathrm{Rp} 2.000 / \mathrm{Kg}$. Berdasarkan hasil penelitian tingkat efisiensi saluran pemasaran Bawang Merah Desa Banti saluran II lebih efisien yaitu $3,85 \%$ dan share yang diterima tiap lembaga lebih besar dari share marjin.
Sesuai dengan yang dikemukakan oleh Nengsih (2012) yaitu jika shere yang diterima petani lebih besar dari shere marjin pemasarannya maka saluran pemasaran tersebut dikategorikan efisien.

\section{DAFTAR PUSTAKA}

Arwanti, Sitti. 2016. Sistem Pemasaran dan Nilai Tambah Produk Olahan Ubi Jalar Kecamatan Polongbangkeng Utara Kabupaten Takalar. Jurnal Program Studi Agribisnis, Universitas Muhammadiyah Makassar.

Ardhiana, M. Y .Nugroho,B.A.Hartono,B. 2014. Efisiensi Pemasaran Telur Ayam Ras Di Kecamatan Ringinrejo Kabupaten Kediri

Resky Mayasari, Z. S. dan Nurhapsa 2017. Pola Distribusi dan Margin Pemasaran Bawang Merah di Kota Parepare

Ningsih, Kustiawati. 2012. Analisis Saluran dan Marjin Pemasaran Petani Jambu Air Camplong (syzygium aqueum), jurnal Fakultas Pertanian, Universitas Islam Madura vol 3 No 1

Pabbo, Baharuddin. 2013. Analisis Marjin Pemasaran Sapi Bali Pada Kelompok Tani Ramah Lingkungan di Desa Galung Kecamatan Barru Kabupaten Barru. Skripsi 
Agribisnis, Fakultas Pertanaian

Peternakan dan Perikanan,

Universitas Muhammadiyah

Parepare.

Roesmawaty, 2011. Analisis Efisiensi

Pemasaran. Jurnal Agribisnis

Rupia.2008. Sistem Pemasaran Kacang

Tanah di Kelurahan Wattang

Bacukikit Kecamatan Bacukikik

Kota Parepar, Skripsi. Agribisnis,

Fakultas Pertanian Peternakan dan

Perikanan, Universitas

Muhammadiyah Parepare.

Sugiyono. 2010. Metode Penelitian

Kuantitatif, Kualitatif, dan R \& D.

Bandung : Alfabeta. 